\title{
SECOND-ORDER DIFFERENTIAL EQUATIONS: SOME SIGNIFICANT RESULTS DUE TO JAMES S.W. WONG
}

\author{
QINGKAI KONG AND MERVAN PAŠIĆ
}

\begin{abstract}
Wong's contribution in the qualitative theory of second-order differential equations is well-known to a large mathematical auidence. Among a huge number of published Wong's papers, in this survey article, we analyze only a few Wong's theorems including their consequences, examples and many influences to other mathematicians dealing with oscillations of second-order differential and functional differential equations as well as of corresponding dynamic equations on time scales.
\end{abstract}

Mathematics subject classification (2010): 34B.

Keywords and phrases: oscillation, second-order differential equation.

\section{REFERENCES}

[1] R.P. Agarwal, M. Bochner, W.T. Li, Nonoscillation and Oscillation: Theory for Functional Differential Equations, Marcel Dekker, New York, 2004.

[2] R.P. Agarwal, S.R. Grace, D. O'Regan, Oscillation Theory for Second Order Linear, Half-Linear, Superlinear and Sublinear Dynamic Equations, Kluwer Academic, Dordrecht, 2002.

[3] R.P. Agarwal, A. Zafer, Oscillation criteria for second-order forced dynamic equations with mixed nonlinearities, Advances in Difference Equations Volume 2009, Article ID 938706, 20 pages.

[4] R.P. Agarwal, D.R. Anderson and A. Zafer, Interval oscillation criteria for second-order forced delay dynamic equations with mixed nonlinearities, Comp. Math. Appl. 59 (2010), 977-993.

[5] W.O. Amrein, A.M. Hinz, D.P. Pearson, Sturm-Liouville Theory: Past and Present, Birkhäuser Verlag Basel, 2005.

[6] D.R. Anderson, Interval criteria for oscillation of nonlinear second-order dynamic equations on time scales, Nonlinear Analysis 69 (2008), 4614-4623.

[7] D.R. Anderson, A. Zafer, Nonlinear oscillation of second-order dynamic equations on time scales, Applied Mathematics Letters 22 (2009), 1591-1597.

[8] Y. Bai, L. Liu, New oscillation criteria for second-order delay differential equations with mixed nonlinearities, Discrete Dyn. Nat. Soc. 2010, Article ID 796256, 9 p. (2010).

[9] E.F. Beckenbach, R. Bellman, Inequalities, Springer, Berlin, 1961.

[10] A.S. Besicovitch, Almost Periodic Functions, Cambridge University Press, Dover Publications, 1954.

[11] H. Brezis, Functional Analysis, Sobolev Spaces and Partial Differential Equations, Springer 2010.

[12] G. J. Butler, Integral averages and the oscillation of second order ordinary differential equations, SIAM J. Math. Anal. 11 (1980), 190-200.

[13] G.J. Butler, L.H. Erbe and A.B. Mingarelli, Riccati techniques and variational principles in oscillation theory for linear systems, Trans. Amer. Math. Soc. 303 (1987), 263-282.

[14] D. Cakmak, A. Tiryaki, Oscillation criteria for certain forced second-order nonlinear differential equations, Appl. Math. Letters 17 (2004), 275-279.

[15] Y.M. Chen, Some oscillation criteria for second-order nonlinear differential equations, J. Math. Anal. Appl. 64 (1978), 610-619.

[16] G. Chen, Announcement: Dr. James Sai-Wing Wong, new Honorary Editor of the JMAA, J. Math. Anal. Appl. 405 (2013), 345-348. 
[17] Y.Z. Chen, L.C. Wu, Second Order Elliptic Equations and Elliptic Systems, Translation of Mathematical Monographs, Amer. Math. Soc., Vol. 174, 1998.

[18] W.J. Coles, An oscillation criterion for second-order linear differential equations, Proc. Amer. Math. Soc. 19 (1968), 755-759.

[19] W.A. Coppel, Disconjugacy, Lecture Notes in Mathematics, Springer-Verlag, Berlin-Heidelberg-New York, 1971.

[20] O. Došlý, S. Fišnarová, Variational technique and principal solutions in half-linear oscillation criteria, Appl. Math. Comp. 217 (2011), 5385-5391.

[21] O. Došlý, A. Özbekler and R. Šimon Hilscher, Oscillation criterion for half-linear differential equations with periodic coefficients, J. Math. Anal. Appl. 393 (2012), 360-366.

[22] O. Došlý, P. Rehak, Half-Linear Differential Equations, Mathematics Studies 202, North Holand, 2005.

[23] Á. Elbert, Oscillation/nonoscillation criteria for linear second order differential equations, J. Math. Anal. Appl. 226 (1998), 207-219.

[24] M.A. El-Sayed, An oscillation criterion for a forced second-order linear differential equation, Proc. Amer. Math. Soc. 118 (1993), 813-817.

[25] M.M.A. El-Sheikh, Oscillation and nonoscillation criteria for second order nonlinear differential equations I, J. Math. Anal. Appl. 179 (1993), 14-27.

[26] L.H. Erbe, Q. Kong, B.G. Zhang, Oscillation theory for functional differential equations, Pure and Applied Mathematics, Marcel Dekker 190, New York, 1994.

[27] L. Erbe, A. Peterson and S.H. Saker, Oscillation criteria for a forced second-order nonlinear dynamic equation, J. Difference Equ. Appl 14 (2008), 997-1009.L. Erbe

[28] L.C. Evans, R.F. Gariepy, Measure Theory and Fine Properties of Functions, Studied in Advanced Mathematics CRC Press, 1992.

[29] T.I. Fossen, H. Nijmeijer, Editors, Parametric Resonance in Dynamical Systems, Springer, New York, 2012.

[30] E. Gagliardo, Sui criteri di oscillazione per gli integrali di un' equazione differenziale linear del secondo ordine, Boll. Unione Mat. Ital. 9 (1954), 177-189.

[31] J.R. Graef, P.W. Spikes, Sufficient conditions for nonoscillation of a second order nonlinear differential equation, Proc. Amer. Math. Soc. 50 (1975), 289-292.

[32] S.R. Grace, B.S. Lalli, Oscillation theorems for certain second order perturbed nonlinear differential equations, J. Math. Anal. Appl. 77 (1980), 205-214.

[33] S.R. Grace, B.S. Lalli, An oscillation criterion for certain second order strongly sublinear differential equations, J. Math. Anal. Appl. 123 (1987), 584-588.

[34] S.R. Grace, B.S. Lalli, Integral averaging technique for the oscillation of second order nonlinear differential equations, J. Math. Anal. Appl. 149 (1990), 277-311.

[35] Z. Guo, X. Zhou, W.-S. Wang, Interval Oscillation criteria for super-half-linear impulsive differential equations with delay, Journal of Applied Mathematics Volume 2012, Article ID 285051, 22 pages.

[36] A.F. Guvenilir, Interval oscillation of second-order functional differential equations with oscillatory potentials, Nonlinear Analysis 71 (2009), 2849-2854.

[37] S.G. Halvorsen and A.B. Mingarelli, On the oscillation of almost-periodic Sturm-Liouville operators with an arbitrary coupling constant, Proc. Amer. Math. Soc. 97 (1986), 269-272.

[38] G.G. Hamedani, G.S. Krenz, Oscillation criteria for certain second order differential equations, J. Math. Appl. Anal. 149 (1990), 271-276.

[39] P. Hartman, On nonoscillatory linear differential equations of second order, Amer. J. Math. 74 (1952), 389-400.

[40] P. Hartman, Ordinary Differential Equations, John Wiley \& Sons, New York, 1964; Second Edition, Birkhäuser Boston, 1982; Second Edition, SIAM-Society for Industrial and Applied Mathematics, Classics In Applied Mathematics 38, Philadelphia, 2002.

[41] Interval oscillation for second order nonlinear differential equations with a damping term, Serdica Math. J. 34 (2008), 715-732.

[42] T.S. Hassan, L. Erbe, A. Peterson, Forced oscillation of second order differential equations with mixed nonlinearities, Acta Mathematica Scientia 31B(2) (2011), 613-626.

[43] T.S. Hassan, Q. Kong, Interval criteria for forced oscillation of differential equations wiht $p$ Laplacian, damiping and mixed nonlinearities, Dynamic Systems and Applications 20 (2011), 279294. 
[44] T.S. Hassan, Q. Kong, Interval criteria for forced oscillation of differential equations with $p$-Laplacian and nonlinearities given by Riemann-Stieltjes integrals, Korean Math. Soc. 49 (2012), 1017-1030.

[45] C. Huang, Oscillation and nonoscillation for second order linear differential equations, J. Math. Anal. Appl. 210 (1997), 712-723.

[46] I.V. Kamenev, Certain specifically nonlinear oscillation theorems, Mat. Zametki 10 (1971), 129-134. (Russian)

[47] I.V. Kamenev, Integral criterion for oscillations of linear differential equations of second order, Mat. Zametki 23 (1978), 249-251.

[48] W. G. Kelley and A. C. Peterson, The Theory of Differential Equations. Classical and Qualitative, Second Edition, Springer, 2010.

[49] V. Komkov, A generalization of Leighton's variational theorem, Applicable Analysis 2 (1972), 377383.

[50] Q. Kong, Interval criteria for oscillation of second-order linear ordinary differential equations, J. Math. Anal. Appl. 229 (1999), 258-270.

[51] Q. Kong, Oscillation criteria for second order half-linear differential equations, Fields Institute Communications, 21 (1999), 317-323.

[52] Q. Kong, Nonoscillation and oscillation of second order half-linear differential equations, J. Math. Appl. 332 (2007), 512-522.

[53] A. Korenovskii, Mean Oscillations and Equimeasurable Rearrangements of Functions, Lecture Notes of the Unione Mathematica Italiana, Springer-Verlag, 2007.

[54] T. Kura, Oscillation theorems for a second order sublinear ordinary differential equation, Proc. Amer. Math. Soc. 84 (1982), 535-538.

[55] M.K. Kwong, J.S.W. Wong, Oscillation and nonoscillation of Hill's equation with periodic damping, J. Math. Anal. Appl. 288 (2003), 15-19.

[56] M.K. Kwong, J.S.W. Wong, A nonoscillation theorem for superlinear Emden-Fowler equations with near-critical coefficients, J. Differential Equations 238 (2007), 18-42.

[57] W. Leighton, Comparison theorems for linear differential equations of second order, Proc. Amer. Math. Soc 13 (1962), 603-610.

[58] H.J. Li, Oscillation criteria of second order linear differential equations, J. Math. Anal. Appl. 194 (1995), 217-234.

[59] W.T. Li, Oscillation of certain second-order nonlinear differential equations, J. Math. Anal. Appl. 217 (1998), 1-14.

[60] W.T. Li, R.P. Agarwal, Interval oscillation criteria for second-order nonlinear differential equations with damping, Comp. Math. Appl. 40 (2000), 217-230.

[61] W.T. Li, R.P. Agarwal, Interval oscillation criteria related to integral averaging technique for certain nonlinear differential equations, J. Math. Anal. Appl. 245 (2000), 171-188.

[62] W.T. Li, S.S. Cheng, An oscillation criterion for nonhomogeneous half-linear differential equations, Appl. Math. Letters 15 (2002), 259-263.

[63] W.T. Li, H.F Huo, Interval oscillation criteria for nonlinear second-order differential equations, Indian J. Pure Appl. Math 32 (2001), 1003-1014.

[64] S. Murugadass, E. Thandapani, S. Pinelas, Oscillation criteria for forced second-order mixed type quasilinear delay differential equations, Electronic Journal of Differential Equations, Vol. 2010(2010), No. 73 , pp. 1-9.

[65] M. Naito, Integral averages and the asymptotic behavior of solutions of second order ordinary differential equations, J. Math. Anal. Appl. 164 (1992), 370-380.

[66] M. Naito, Integral averaging techniques for the oscillation and nonoscillation of solutions of second order ordinary differential equations, Hiroshima Math. J. 24 (1994), 657-670.

[67] A.K. Nandakumaran and S. Panigrahi, Oscillation criteria for differential equations of second order, Math. Slovac 59 (2009), 433-454.

[68] A.H. Nasr, Sufficient conditions for te oscillation of forced super-linear second order differential equations with oscillatory potential, Proc. Amer. Math. Soc. 126 (1998), 123-125.

[69] A.H. Nayfeh, D.T. Mook, Nonlinear Oscillations, New-York, Wiley, 1979.

[70] H. Onose, Oscillation criteria for second order nonlinear differential equations, Proc. Amer. Math. 51 (1975), 67-73.

[71] M. Pašić, New oscillation criteria for second-order forced quasilinear functional differential equations, Abstract and Applied Analysis, Volume 2013, Article ID 735360, 12 pages, (2013). 
[72] M. Pašić, New interval oscillation criteria for forced second-order differential equations with nonlinear damping, Int. Journal of Math. Analysis, Vol. 7, 2013, no. 25, 1239-1255.

[73] M. Pašić, Fite-Wintner-Leighton-type oscillation criteria for second-order differential equations with nonlinear damping, Abstract and Applied Analysis Volume 2013, Article ID 852180, 10 pages.

[74] M. Pašić, Parametrically excited oscillations of second-order functional differential equations and application to Duffing equations with time delay feedback, to appear.

[75] Ch. G. Philos, Oscillation of sublinear differential equations of second order, Nonlinear Anal. 7 (1983), 1071-1080.

[76] Ch. G. Philos, Oscillation theorems for linear differential equations of second order, Arch. Math. 53 (1989), 482-492.

[77] Ch. G. Philos and I.K. Purnaras, Oscillations in superlinear differential equations of second order, J. Math. Anal. Appl. 165 (1992), 1-11.

[78] C.R. Putnam, Note on some oscillation criteria, Proc. Amer. Math. Soc. 6 (1955), 950-952.

[79] Y.V. Rogovchenko, Note on "Oscillation Criteria for Second Order Linear Differential Equations", J. Math. Anal. Appl. 203 (1996), 560-563.

[80] Y.V. Rogovchenko, Oscillation criteria for certain nonlinear differential equations, J. Math. Anal. Appl. 229 (1999), 399-416.

[81] Y.V. Rogovchenko, F. Tuncay, Interval oscillation of a second order nonlinear differential equation with a dampong term, Discrete abd continuous dynamical systems, Supplement (2007), 883-891.

[82] J. Shao, F. Meng, X. Pang, Generalized variational oscillation principles for second-order differential equations with mixed- nonlinearities, Discrete Dynamics in Nature and Society, Volume 2012, Article ID 539213, 10 pages, (2012).

[83] W. Shi, Interval oscillation criteria for a forced second-order differential equation with nonlinear damping, Mathematical and Computer Modelling 443 (2006), 170-177.

[84] N. Shang and H. Qin, Comments on the paper: "Oscillation of second-order nonlinear ODE with damping" [Applied Mathematics and Computation 199 (2008) 644-652], Applied Mathematics and Computation, vol. 218, no. 6, (2011), 2979-2980.

[85] S. Stanek, A note on the oscillation of solutions of the differential equation $y^{\prime \prime}=\lambda q(t) y$ with a periodic coefficient, Czechoslovak Mathematical Journal, Vol. 29 (1979), 318-323.

[86] J. Sugie and K. Matsumura, A nonoscillation theorem for half-linear differential equations with periodic coefficients, Appl. Math. Comput. 199 (5) (2008), 447-455.

[87] Y.G. Sun, A note on Nasr's and Wong's papers, J. Math. Anal. Appl. 286 (2003), 363-367.

[88] Y.G. Sun, C.H. Ou, J.S.W. Wong, Interval oscillation theorems for a second-order linear differential equation, Comp. Math. Appl. 48 (2004), 1693-1699.

[89] Y.G. Sun, F.W. Meng, An improvement on the oscillation of forced second order nonlinear differential equations, New Zeland Journal of Mathematics 35 (2006), 201-206.

[90] Y.G. Sun, F.W. Meng, Interval criteria for oscillation of second-order differential equations with mixed nonlinearities, Appl. Math. Comp. 198 (2008), 375-381.

[91] Y.G. Sun, Q. Kong, Interval criteria for forced oscillation with nonlinearities given by RiemannStieltjes integrals, Computers and Mathematics with Applications 62 (2011), 243-252.

[92] Y.G. Sun, J.S.W. Wong, Oscillation criteria for second order forced ordinary differential equations with mixed nonlinearities, J. Math. Anal. Appl. 334 (2007), 549-560.

[93] Y. Sun, Z. Han, S. Sun and C. Zhang, Interval oscillation criteria for second-order nonlinear forced dynamic equations with damping on time scales, Abstract and Applied Analysis Volume 2013, Article ID 359240, 11 pages.

[94] C.A. Swanson, Comparison and Oscillation Theory of Linear Differential Equations, Academic Press, New York and London, 1968.

[95] C. C. Travis, Oscillation theorems for second order differential equations with functional arguments, Proc. Amer. Math. Soc. 31 (1972), 199-202.

[96] E. Tunc and $\mathrm{H}$. Avci, Interval oscillation criteria for second order nonlinear differential equations with nonlinear damping, Miskolc Mathematical Notes 14 (2013), 307-321.

[97] J. Tyagi, An oscillation criteria for second-order linear differential equations, Nonlinear Dynamics and Systems Theory 11 (2011), 93-97.

[98] Q.R. Wang, Interval criteria for oscillation of second-order nonlinear differential equations, Journal of Computational and Applied Mathematics 205 (2007), 231-238. 
[99] D. Willett, Classification of second order linear differential equations with respect to oscillation, Adv. Math. 3 (1969), 594-623.

[100] A. Wintner, A criterion of oscillatory stability, Quart. Appl. Math. 7 (1949), 115-117.

[101] J.S.W. Wong, Oscillation and nonoscillation of solutions of second order linear differential equations with integrable coefficients, Trans. Amer. Math. Soc. 144 (1969), 197-215.

[102] J.S.W. Wong, A second order nonlinear oscillation theorem, Proc. Amer. Math. Soc. 40 (1973), $487-$ 491.

[103] J.S.W. Wong, An oscillation criterion for second order nonlinear differential equations, Proc. Amer. Math. Soc. 98 (1986), 109-112.

[104] J.S.W. Wong, Second order nonlinear forced oscillations, SIAM J. Math. Anal. 19 (1988), 667-675.

[105] J.S.W. Wong, An oscillation criterion for second order nonlinear differential equations with iterated integral averages, Differential and Integral Equations 6 (1993), 83-91.

[106] J.S.W. Wong, A sublinear oscillation theorem, J. Math. Anal. Appl. 139 (1989), 408-412.

[107] J.S.W. Wong, Oscillation theorems for second-order nonlinear differential equations, Proc. Amer. Math. Soc. 106 (1989), 1069-1077.

[108] J.S.W. Wong, Oscillation criteria for a forced second-order linear differential equation, J. Mat. Anal. Appl. 231 (1999), 235-240.

[109] J.S.W. Wong, Oscillation criteria for second order nonlinear differential equations involving general means, J. Math. Anal. Appl. 247 (2000), 489-505.

[110] J.S.W. Wong, On Kamenev-type oscillation theorems for second-order differential equations with damping, J. Math. Anal. Appl. 258 (2001), 244-257.

[111] J.S.W. Wong, On an oscillation theorem of Waltman, Canadian Applied Mathematics Quarterly 11 (2003), 415-432.

[112] J.S.W. Wong, Remarks on a paper of C. Huang, J. Math. Anal. Appl. 291 (2004), 180-188.

[113] J.S.W. Wong and C.C. Yeh, An oscillation criterion for second order sublinear differential equations, J. Math. Anal. Appl. 171 (1992), 346-351.

[114] Z. Xu, S. Peng, Interval criteria for oscillation of second order half-linear differential equations with damping, Tamkang Journal of Mathematics 36 (2005), 49-56.

[115] J. Yan, A note on an oscillation criterion for an equation with damped term, Proc. Amer. Math. Soc. 90 (1984), 277-280.

[116] J. Yan, Oscillation theorems for second order linear differential equations with damping, Proc. Amer. Math. Soc. 98 (1986), 276-282.

[117] Q.G. Yang, Interval oscillation criteria for a forced second order nonlinear ordinary differential equation with oscillatory potential, Appl. Math. Comput. 135 (2003), 49-64.

[118] Q. Yang, R.M. Mathsen, Interval oscillation criteria for second order nonlinear delay differential equation, Rocky Mountain Journal of Mathematics 34 (2004), 1539-1563.

[119] C.C. Yeh, An oscillation criterion for second order nonlinear differential equations with functional arguments, J. Math. Anal. Appl. 76 (1980), 72-76.

[120] C.C. Yeh, Oscillation theorems for nonlinear second order differential equations with damped term, Proc. Amer. Math. Soc. 84 (1982), 397-402.

[121] C.C. Yeh, Oscillation criteria for second order nonlinear perturbed differential equations, J. Math. Anal. Appl. 138 (1989), 157-165.

[122] Y.H. Zeng, Interval oscillation of nonlinear differential equation with damped term, Communications in Information Science and Management Engineering 3 (2013), 127-134.

[123] Z. Zheng, F. Meng, Oscillation criteria for forced second-order quasi-linear differential equations, Mathematical and Computer Modelling 45 (2007), 215-220.

[124] Z. Zheng, X. Wang, H. Han, Oscillation criteria for forced second order differential equations with mixed nonlinearities, Applied Mathematics Letters 22 (2009), 1096-1101. 